\title{
Focusing on Ethics and Broadening our Intellectual Base
}

\author{
Michelle Greenwood $^{1} \cdot$ R. Edward Freeman ${ }^{2}$
}

Published online: 9 January 2017

(C) Springer Science+Business Media Dordrecht 2017

As we complete our first year as editors in chief at the Journal of Business Ethics (JBE), we would like to share with you our thinking that underpins the changes which, together with the editorial team, we are making at the journal. Notably, we believe that we need to focus the scope of the journal clearly on ethics, while broadening the intellectual base of the journal.

Business ethics has its intellectual and historical roots in philosophy and religious ethics. In today's world, the very idea of business is often relegated to an overly narrow conception of economic activity. However, business is increasingly viewed as an important societal institution across the globe. It has significant consequences for the wellbeing of human society. Difficult ethical issues such as climate change, poverty, and basic human rights require multiple modes of analysis. No single academic discipline has a monopoly on useful ideas that will help us all to live better in the twenty-first century. It is only logical that we bring the full arsenal of relevant disciplines to create new narratives and improve current ideas that can make the institution of business a greater servant of humanity.

We believe that sociologists, psychologists, economists, critical theorists, and humanities thinkers all have something to contribute to business ethics. Therefore, we have created some new sections of the journal ${ }^{1}$ to encourage

Michelle Greenwood

michelle.greenwood@monash.edu

1 Monash Business School, Monash University, Melbourne, VIC, Australia

2 Darden Business School, University of Virginia, Charlottesville, VA, USA academics in those areas to turn their attention to business ethics. Additionally, we wish to stimulate alternative thinking by traditional business ethics scholars as they come into contact with new models, concepts, and theories. By broadening the intellectual base of business ethics, we hope to encourage interdisciplinary thinking and the creation of new and useful ideas that will reinvigorate our scholarship as well as the practice of business.

We also believe that "ethics" is the most important word in the title of the journal. We expect that a focus on ethics will be central to all the papers in $J B E$ and want to re-emphasize here that the papers in the journal need to be concerned explicitly with ethical analysis and framing. We do not have a particular point of view about what counts as "ethical analysis". Psychologists and sociologists may well see "ethics" and "ethical analysis" in a different light to philosophers. The very idea of "ethics" has been contested throughout civilizations around the world, and we hope to encourage a pluralist point of view. This conversation about the scope of "ethics" and "ethical analysis" is a healthy one that we encourage in the pages of the journal.

Business models, polices, practices, and behaviours are often presented as if they are prima facie "ethical", or for that matter "ethically neutral" or "unethical". Subjects that may give the appearance of being inherently ethical include many of the key themes explored in the journal such as sustainability, social entrepreneurship, and corporate governance. Scholars may be under the mistaken impression that merely writing about such topics brings them in scope of the journal. This is not so; it is incumbent upon the author/s to clearly explain how they understand

\footnotetext{
${ }^{1}$ For a full description of these new sections and other sections at the journal please go to the Journal of Business Ethic's website at http:// www.springer.com/philosophy/ethics+and+moral+philosophy/jour $\mathrm{nal} / 10551$.
} 
their phenomenon and to make the connection to ethics that they believe exists. Authors need to critically explore and assess the dimensions of the phenomena they are studying, and to link it to the work of other scholars. Let us give some examples of what we have in mind from articles recently published by the journal online. ${ }^{2}$

Consider the business practice of fair trade. The ethically laden term "fair trade" has in many instances become an empty signifier representing certification practices or merely opportunistic marketing. In their paper exploring fair trade activism, Peattie and Samuels (2016) do not just assume their readers understand or agree with the their own understanding of ethical activism, but explain at length what they mean by "ethically motivated shareholder or consumer activism", placing it in the context of broad social movements and as involving direct or indirect influence enacted though a range of activities. The aim of the paper is centrally concerned with the ethical aspects of fair trade towns (FTT): "This paper seeks to further our understanding of FTTs as an ethical marketing phenomenon by exploring the role played by activism and by activists as marketing system change agents." The authors have immersed themselves in the phenomenon both explaining how the phenomenon may be understood as ethical, and placing ethical concerns about the phenomenon central to their investigation.

In contrast, the experience and management of chronic illness in the workplace is an example of a phenomenon that might or might not be considered as a deeply ethical matter. This could be approached by treating chronic illness as an employee trait or characteristic (one that would render the employee as either vulnerable or troublesome in the context of the workplace) and study how this trait might be managed under various "ethical" or "unethical" conditions. However, such a study of "ethics" is at risk of foreclosing on both the ontology of the phenomenon (by treating chronic illness as a thing that exists or does not exist) and ethics (by presenting ethics as a known, unidimensional object). In contrast to such an approach, Vijayasingham et al. (2016) explore the experience of chronic illness from an ethics of care perspective. They propose the idea of organisational caregiving as "building

\footnotetext{
${ }^{2}$ For a complete list of articles published by the journal online first please go to please go to the Journal of Business Ethic's website at http://www.springer.com/philosophy/ethics+and+moral+philoso phy/journal/10551.
}

on the role of supportive work environments and positive interpersonal resources in facilitating work participation and retention." Treating the phenomenon of chronic illness as a situated and relational experience allowed the authors to explore the ways in which organisations, managers, and co-workers can contribute to the practice of business ethics.

Behaviours that are considered "unethical" are often behaviours that have been labelled as negative or undesirable from either a psychological or a sociological perspective. For example, a lack of connection to social mores and/or a lack of compassion might be assumed to be associated with "unethical" behaviours. We contend that such associations need to not merely be assumed, but ought to be critically explored. In their study of anomia and its relationship to deviance in the workplace, Zoghbi-Manrique-de-Lara and Guerra-Báez (2016) do not limit their exploration to either a sociological reading or a psychological reading of the concept; rather they combine these to develop an explicit business ethics perspective (c.f. Tsahuridu 2011). They explore their contention that "anomic staff can believe it is ethically justifiable to engage in workplace deviance when following the route of deactivating the moral obligation to be compassionate" through traditional psychological scales, but analyse these findings in the context of the socio-political conditions of organisations and businesses. In doing so, the authors have critically engaged with not only the "ethics" but also the "business" of business ethics.

These examples are three among many possible ones that we could have given. What we are asking of our authors, reviewers, and editors is to pay close attention to the "ethics" inherent in each paper, and to make ethical analysis, in whatever guise, an explicit part of the arguments. If we can focus the scope of the journal while broadening the intellectual base, we can enrich the conversation about business ethics, and perhaps create some new narratives that will make business better.

We have been fortunate to inherit a journal with a considerable history and legacy, and we feel privileged to have to opportunity to make our mark on it. Of the many changes made to the journal in the last year the most immediately noticeable are at a visual level, with the new logo and cover design gracing this issue for the first time. We would like to celebrate the completion of this exciting first year with our heartfelt thanks and acknowledgement of the extraordinary work by the editorial team: our section editors and consulting editors, both those with a long history with the journal and those new to the team; our editorial board and reviewers; and of course our authors. A special note of appreciation to the Springer team, in particular Mr Sivakani Jayaprakesh, without whom we would not be able to publish even a word. 


\section{References}

Peattie, K., \& Samuel, A. (online 2016). Fairtrade towns as unconventional networks of ethical activism. Journal of Business Ethics. doi:10.1007/s10551-016-3392-3.

Tsahuridu, E. E. (2011). An exploration of factors affecting work anomia. Journal of Business Ethics, 99(2), 297-305.

Vijayasingham, L., Jogulu, U., \& Allotey, P. (online 2016). Enriching the organizational context of chronic illness experience through an ethics of care perspective. Journal of Business Ethics. doi:10. 1007/s10551-016-3362-9.

Zoghbi-Manrique-de-Lara, P., \& Guerra-Báez, R. M. (online 2016). A study of why anomic employees harm co-workers: Do uncompassionate feelings matter? Journal of Business Ethics. doi:10. 1007/s10551-016-3313-5. 